\title{
The death and resurrection of 'economics with psychology': remarks from a methodological standpoint
}

ROBERTA MURAMATSU*

One of the merits of contemporary economic analysis is its capacity to offer accounts of choice behavior that dispense with details of the complex decision machinery. The starting point of this paper is the concern with the important methodological debate about whether economics might offer accurate predictions and explanations of actual behavior without any reference to psychological presuppositions. Inspired by an exercise of rational reconstruction of ideas, I aim to offer an interpretation of the process of freeing economic analysis from psychology at the end of the $19^{\text {th }}$ century and the contemporary resurrection of behavioral approaches in the late 1980 s.

Keywords: economics; psychology; anomalies; prediction; explanation.

JEL Classification: B10; B20; B40.

Is it not patently unrealistic to suppose that individuals... base their decisions on the size of an expected utility? (...) This objection is not strictly relevant. (...) The validity of this assertion does not depend on whether individuals know the precise odds... or whether psychologists can uncover any evidence that they do, but on whether it yields sufficiently accurate predictions. Friedman and Savage, "The Utility Analysis Involving Risk"

Journal of Political Economy, pp. 279-80

Ceteris paribus, the more realistic our assumptions about economic actors, the better our economics. Hence, economists should aspire to make our assumptions... as psychologically realistic as possible.

M. Rabin, "A Perspective on Economics and Psychology"

European Economic Review, p. 658

* Assistent/Associate Professor of Economics at Mackenzie University of São Paulo and Senior Lecturer, Ibmec Business School, São Paulo. rmuramatsu@uol.com.br. Submitted: April 2007; Approved: October 2007. 


\section{INTRODUCTION}

One of the merits of standard economic analysis is its capacity to offer parsimonious accounts of choice that dispense with details of the complex decision machinery. Despite the existence of many critics of the behavioral foundations of economic theory of choice (Simon, 1955; Sen, 1977), there is a long-standing tradition of assessing the goodness of an economic model or theory only by reference to its predictive implications, regardless of its unrealistic assumptions (Friedman, 1953).

These methodological issues still intrigue contemporary economists and give rise to doubts about the possibility of developing satisfactory economic explanations of behavior cleansed from psychological presuppositions (Sugden, 1991; Rabin, 2002; Bruni and Sugden, 2007). Inspired by an exercise of rational reconstruction of ideas ${ }^{1}$, this paper provides an interpretation of why economists of the $20^{\text {th }}$ century worked hard to develop 'economics without psychology'. Additionally, the current work draws on a vast literature about the shifting relations between economists and psychologists that shed light on the resurrection of 'economics with psychology' in the late 1980s (Lewin, 1996; Rabin, 1998; Camerer and Loewenstein, 2004). I will go on to suggest that systematic and recurrent evidence about deviations from predictions by the standard economic models of choice, often regarded as anomalies, led economists to exchange theoretical and empirical knowledge with psychologists, sociologists, neuroscientists and evolutionary biologists so as to make their tractable accounts of judgment and decisionmaking as congruent with reality as possible (Rabin, 1998; Schiller, 2001; Bowles, and Gintis, 2003; Camerer, Loewenstein and Prelec, 2005).

The overall argument is built on the conjecture that an ongoing problem posed to economists is the construction of models and theories that effectively meet their purposes of prediction. I argue that two methodological challenges might explain why economists worked on economic models purged of (explicit) psychology, whereas two other troubling issues led contemporary choice theorists to construct models with explicit psychological items. To undertake the above tasks, I analyze the standard model of human action offered by late- $19^{\text {th }}$ century economists and diagnose two methodological difficulties: one is the "measurability of cardinal utility" and another concerns reliance on psychological hedonism as a basis for scientific economic theorizing. I argue that the foregoing problems offer reasons for purging economic models from psychology. This article detects two other philosophical problems that account for the revival of psychological economic accounts: (a) the rise of significant choice anomalies, and (b) the comparative advantages of building up economic models that uncover empiricallygrounded processes or mechanisms for behavior.

This paper is structured as follows. The second section discusses how Stanley Jevons and Francis Edgeworth relied on psychological hedonism to explain behav-

\footnotetext{
${ }^{1}$ The method owes much to Professor Blaug's (2001) ideas on historiography.
} 
ior within the realm of market exchange. The third section highlights non-negligible methodological issues posed by Benthamite utilitarianism that led to the development of an alternative to the notion of utility cleansed from a debatable psychological doctrine. The fourth section discusses attempts to purge utility theory of psychology, and in particular the work of Vilfredo Pareto (1900a, 1900b, 1906), Eugene von Slutsky (1915), and Paul Samuelson (1938). The fifth section shows how economists came to explain behavior without an appeal to explicit psychology. The sixth section discusses why and how prediction of anomalies and identification of processes or mechanisms for behavior partly guide the resurrection of psychological economics. The seventh section wraps the whole story up and concludes.

\section{ECONOMICS AND PSYCHOLOGICAL HEDONISM}

In his Introduction to the Principles of Morals and Legislation, Jeremy Bentham (1789: 1) postulates that the pursuit of pleasure (and avoidance of pain) explains all human action and even serves as a criterion to evaluate the propriety of behavior. His ideas gave rise to accounts in terms of the hedonic utility principle.

Bentham's psychological hedonist framework ascribes a central role to utility in the explanation of behavior. The very concept of utility was regarded as a cardinal measure of pleasure, happiness among other affective experiences. Disutility referred to negative affects that individuals avoided. In such perspective, utility and disutility amount to properties of any object or commodity. The notion of the rationality of human action depends on conformity with the principle of maximum utility. Given the importance of this notion for leading $19^{\text {th }}$ century economists, the appeal of Bentham's approach to economic action is worth examining.

\section{Hedonic utility and explanation of economic facts}

Unlike the classical tradition of Political Economy, which invoked labor value theory to address the issues of economic growth and wealth distribution, many economists of the 1870s took Bentham's doctrine of psychological hedonism as inspiration for an alternative value theory that would give a rigorous treatment of prices, resource allocation and market behavior. This shift in the explanantia and explananda was one of the hallmarks of the Marginal Revolution in economic thought (Black, Coats and Goodwin, 1973; Blaug 1997)².

The first generation of marginalist economists used Bentham's notion of (car-

\footnotetext{
${ }^{2}$ Before the Marginal Revolution of the 1870 s, political economists also derived their accounts of cooperation and exchange behavior from psychological laws or statements about human nature. In his Theory of Moral Sentiments, Smith seems to anticipate Kahneman and Tversky's (1979) ideas that people are more sensitive to losses than to gains. He explicitly says: "we suffer, it has already been observed, when he falls from a better to a worse situation" (Smith 1759, vi.i.7). Mill (1843) investigates the complex psychology and sociology of human preferences so as to explain (economic) behavior.
} 
dinal) utility as an attempt to build a tractable account of behavior that could make economics as scientific as physics. Some regarded the principle of hedonic calculus as a universal law of human nature from which economic relations and exchange behaviors could be deduced. For instance, Jevons ([1871] 1970) drew on Bentham's hedonic utility to explain market phenomena in terms of pleasure-pain calculus, and hypothesized that the decreasing marginal utility principle was analogous to certain regular principles of physics (1970: viii). According to him, value is determined by hedonic utility. In his Theory of Political Economy, pleasure and pain are taken as the ultimate objects of economics, which is thus reduced to pleasure maximization (ibid.: 97). He took this psychological presupposition as necessary to make economics a scientific (and a necessarily mathematical) endeavor. However, Jevons realizes that hedonic calculus might not grasp all the complexity of human action. He suggests that the principle of utility maximization is a simplification of reality that serves the purposes of economics (ibid.: 93).

Francis Edgeworth also assumes that utility amounts to happiness and pleasure as measurable magnitudes. In his article "Hedonical Calculus", Edgeworth appeals to the Benthamite thesis by saying: "pleasure is measurable; and all pleasures are commensurable; so much of one sort of pleasure felt by one sentient being equateable to so much of other sorts of pleasure felt by other sentients (1879: 395). Three years later his Mathematical Psychics attempts to apply quantitative methods - and, in particular, the conceptions and methods of physics - to Political Economy and other moral sciences.

Jevons and Edgeworth had much in common. Both used Bentham's notion of cardinal hedonic utility to construct an improved explanation of behavior. Edgeworth built on Jevons' approach to describe the mechanics of market exchange and under what conditions contracts occur. Both applied quantitative methods to their studies to transform economics into an abstract, deductive and rigorous science.

\section{MOTIVES FOR THE 'DE-PSYCHOLOGIZING' OF ECONOMIC ANALYSIS}

Grounding economics on hedonic utility brought two methodological problems that constrain the economists' chance to develop a discipline with the scientific credentials of physics. They concern the measurability of cardinal utility and usage of psychological hedonism as basis for accounts of market phenomena. These two difficulties offer reasons for economists to develop economic models purged of psychology. I do not argue that utility measurability and the using psychological hedonism as foundation for economic analysis are the actual or sufficient causes of the fall of psychological economic explanations in the late $19^{\text {th }}$ century. Instead, my point is that these methodological problems partly explain why economics centered on hedonic calculus lost its appeal and motivated economic accounts free from psychology. 


\section{Challenges for hedonic utility analysis}

Early marginalist economists remained enthusiastic about the prospect of scientific progress associated with hedonic utility ${ }^{3}$. They did not properly investigate some problems associated with cardinal utility analysis drawing on psychological hedonism. One concerns the existence of an objective measure of agent's pleasures and pains. Another has to do with the use of psychological hedonism as a basis for positive as well as normative accounts of economic behavior.

Jevons struggled to deal with the problem of utility measurability. In the first edition of his Theory, he denied the possibility of measuring utility ([1871] 1970: 12).

Provided that the advancement of utility analysis depended on the existence and measurability of utility, Jevons and his contemporaries proposed that utility be estimated by using the amount of money that the agent spent to acquire the good. Yet an effective solution to this methodological problem would require an accurate way of measuring pleasure and pain. Economists of Jevons' time knew that nothing like one hedonimeter existed. In response to that they downplayed the significance of the measurability problem. Some went to argue that the issue of measurability of utility was not essential to meet their purpose of deriving demand curves (Stigler, 1950). Indeed some applications to the hedonic utility approach highlight the constraints on explanation put by the issue of measurability. Using hedonic utility to make welfare analysis would bring the problem of estimating the utility of a good to an individual and to compare it with affections experienced by others ${ }^{4}$.

A second methodological problem is reliance of psychological hedonism as a basis for economic positive and normative models. Grounding economic explanations on Benthamite utilitarianism brought some embarrassment to economists. The first objections to psychological hedonism came from psychologists. Based on empirical studies, they ridiculed the principle of pain-pleasure calculus and called the doctrine of psychological hedonism unscientific (McDougall, 1910). In his Principles of Psychology, William James argued that a proper explanation of behavior could not be reduced to hedonic calculus, and found no empirical evidence that behavior was driven only by the goal of maximizing pleasure and minimizing pain (1890: 551-5)

Most $19^{\text {th }}$ century economists did not take psychologists' criticism seriously.

\footnotetext{
${ }^{3}$ Stigler (1950: 320).

${ }^{4}$ For a detailed account of the problem of interpersonal comparison of utility, see Sen (1977).

${ }^{5}$ This issue is still a debatable question. According to Bruni and Sugden (2007: 148), neoclassical economics of the nineteenth century did rest on a viable program of scientific psychology. The decreasing marginal utility hypothesis was grounded on empirical research done by psychologists like Fechner and Wundt (ibid.: 151).
} 
Even though they acknowledged the existence of motives for behavior other than pleasure maximization, marginalist economists argued that omissions and simplifications were inevitable (Lewin, 1996: 1300). Institutionalist economists drew upon criticisms made by psychologists in order to suggest reforms in neoclassical economics. Thorstein Veblen (1909) and Ezekiel Downey (1910) argued that standard economic theory failed to explain the rise and persistence of institutions and economic change due to its focus on pain-pleasure calculus ${ }^{6}$. The above attacks to economic analysis gave rise to disputes within the profession. As a result, descents of marginalist revolution opted for building a science of economics free from hedonic psychology ${ }^{7}$. Irving Fisher suggested that utility be independent of psychology and philosophy. To him, economists ought to content themselves with the postulate that each individual acts as he desires $(1892: 5,11)$. Then economists should not waste time working on psychological matters.

In short, finding a proper measure to hedonic utility and using hedonism as basis for positive economic analysis can be interpreted as reasons for the developing a choice-based utility theory.

\section{HOW ECONOMISTS FREED THEIR ACCOUNTS FROM PSYCHOLOGICAL PRESUPPOSITIONS}

Purging economics of psychological terms seemed to involve two stages. One was the gradual shift from theorizing on cardinal hedonic utility to ordinal utility; another was building an explanation in terms of utility and probability axioms without any clear psychological basis.

\section{Ordinal utility theory as a first step towards an 'economics without psychology'}

In response to the philosophical problems underlying hedonic utility theory, economists at the turn of $20^{\text {th }}$ century 'renounced' psychological hedonism. Instead, they worked hard on developing a choice-based utility approach. The latter was expected to offer an answer to the question of how to make utility objective and tractable just like force and energy in physics as well as a 'solution' to the problem of utility measurability.

\footnotetext{
${ }^{6}$ The economist J.M. Clark (1918) claimed that economics could not get rid of psychology. Nevertheless, economists ought to take only 'good psychology' seriously. See Lewin (1996) for details about the institutionalist critique.

${ }^{7}$ Wesley Mitchell (1916: 144-145) suggests that even Alfred Marshall eliminated the hedonistic language of his account of utility and consumer behavior in response to some embarrassment posed by a debatable psychological doctrine
} 
Pareto's contributions

Following the vision that scientific economics could be free from psychology and metaphysics, Pareto (1900a, 1900b, 1906) rejected the hedonist approach and argued that economics wanted to explain facts such as market exchange and price determination.

Pareto's Cours reflects his dissatisfaction with the vague notion of utility. $\mathrm{He}$ agreed on Walras' opinion that utility was not a measurable thing in practice. This interpretation led him to elaborate on an anti-hedonistic perspective. In a letter to Benedetto Croce, he wrote: "nobody is capable of measuring pleasure. Who can say what pleasure is double another pleasure?"(1900a: 183)

However, Pareto tried hard to give a mathematical treatment to utility theory. He proposed to measure the value of utility indirectly through observation of actual phenomena. This methodological procedure, he argued, resembled physicists' methods for determining the length of light waves through the observation of optical phenomena. Pareto explains:

Until now, in order to establish economic doctrines we went back to choice. Choice has been explained as man's aim to achieve maximum pleasure. Between two things, man chooses the one that provides more pleasure. (...) The use of this point of view forces us to consider pleasure as a quantity. And this is what economists have established pure economic theories have done... but we must admit that this is not a thoroughly rigorous method (Pareto 1900b: 221)

Pareto provided a utility theory grounded in human experience. By analyzing empirically derived indifference curves, he deduced a mathematical function that yields an index of the curves that represent an individual preference ordering. This formal treatment of utility would make economics 'more scientific'. In Pareto's own words,

This entire theory... rests only on a fact of experience, that is to say, on the determination of the quantities of goods which constitute combinations between which the individual is indifferent... the theory of economic science acquires the rigor of rational mechanics; it deduces its results from experience, without bringing in any metaphysical entity (1906: 113).

Pareto's proposal of ordinal utility yields an account of behavior patterns without any appeal to subjective factors. Such theoretical movement would meet the purposes of predicting market (exchange) phenomena. He succeeded in devising an explanation that was not committed to hedonism. Alternatively Pareto provided a choice-based treatment. Pareto explains why a systematic study of economic facts can dispense with hedonic psychology: 
Pure economic equations simply express the fact of a choice, and can be obtained independently of the notion of pleasure and pain... For us, it is sufficient to note the fact of individual choice, without investigating the psychological or metaphysical implications of such a choice... Pure economic equations and their consequences exist unchanged whether we start from the consideration of pleasure as a quantity, or we limit our investigation... to the fact of choice (Pareto 1900b: 221-4).

So Pareto took the first step towards the development of utility theory purged of the problems of hedonism. His ideas gave boost to analytical models of exchange behavior. With Walras' and Pareto's contributions economists could advance their capacity to represent phenomena without incurring in the problems of measurability of pleasure and pain. Instead economists began to develop an explanation of market behavior in terms of observable factors.

The development of ordinal utility framework

Eugene Slutsky (1915: 28) followed Pareto and argued that economic explanations could not have a firm scientific basis unless it dispensed with psychological assumptions and metaphysical hypotheses. He argued for an account of utility that referred to an objective scale of individual preferences. Slutsky derived his utility theory from mathematical properties of indifference curves. His analysis in terms of ordinal utility facilitated the development of a satisfactory account of price determination and optimal resource allocation, as well as ridding economics of the embarrassment of hedonic psychology (Stigler, 1950).

Like other economists of the early $20^{\text {th }}$ century Frank Knight (1925) acknowledges some problems of economic accounts committed to controversial psychological doctrines. He claims that the basic difficulty in economic theory is the philosophical problem of explanation and its relation to human behavior (p. 372). With this in mind, he suggests that a choice-based approach to utility be necessary for a positive economic account (ibid.) ${ }^{8}$ Knight emphasized that behaviorism would not contribute to progress in economics but acknowledged that some economists would adhere to it (ibid: 388 ).

As a philosophical doctrine, behaviorism holds the thesis that explanation of behavior dispenses with any reference to mental entities and processes. In this perspective, a scientific explanation is in terms of empirically observable (external)

\footnotetext{
${ }^{8}$ One of Knight's (1921) important contributions was the distinction between risk and uncertainty. Risk amounts to cases where the agent can assign probabilities to random phenomena, whereas uncertainty occurs when randomness cannot be represented by mathematical probabilities (p. 21). This exercise of conceptual analysis inspired behavioral models of choice.
} 
factors. Behaviorism might fit with some economists' view that freeing utility theory from hedonism would allow for a positive account of market exchange 9.

Furthering Slutsky's and Knight's theorizing movements, Hicks and Allen's (1934) work advanced an ordinalist approach to behavior that further dispensed with hedonic psychology by replacing the concept of marginal utility with that of marginal rate of substitution. Their account in terms of the marginal rate of substitution was very welcomed by their peers. However, some remained skeptical in relation to Hicks and Allen's analytical treatment being sufficient; their empirical studies still left room for psychological interpretations. Even though the concept of marginal rate of substitution could deal with the problem of (comparing) cardinal utilities and their difference, there was some room for 'psychology' in this ordinalist perspective because individuals are thought to rank their preferences and act so as to satisfy them. As a result, Hicks and Allen's treatment could not be regarded as an indisputable ex-post rationalization of observed behavior.

\section{Samuelson's contributions}

Samuelson attempted to overcome Hicks and Allen's problem by "dropping off the last vestiges [from psychology] of the utility analysis" (1938: 62, bracket is mine). Driven by his operationalist methodology, he tried to rid utility analysis of the last psychological presuppositions by studying preference ordering and indifference curves based upon actually observed choices ${ }^{10}$. Samuelson complained that economists (like Hicks and Allen) theoretically derived preferences from behavior and therefore had to appeal to some introspection. Alternatively, he argues that preferences are derivable from empirical demand functions. Based on a set of axioms of rational behavior in a choice setting (in which agents were assumed to make internally consistent choices), Samuelson developed his revealed preference theory.

Samuelson hypothesized that if a bundle $\mathrm{x}$ were revealed preferred to another $\mathrm{y}$, there would never be situations in which $\mathrm{y}$ will be preferred to $\mathrm{x}$. His theoretical formulation yielded a natural link between the demand function and individual preferences (observed choices). Hence, Samuelson's theory of revealed preference yielded an economic explanation of behavior that does not rest upon any explicit psychology ${ }^{11}$. Individuals are expected to choose what they want. This is because 'what they want' is, by hypothesis, 'what they (actually) chose'.

In sum, economists in the first half of the $20^{\text {th }}$ century worked to advance a choice-based approach to utility. Unlike the first generation of marginalists, they aimed to remove explicit psychological presuppositions from utility theory. Their

\footnotetext{
${ }^{9}$ For economists' discussion of behaviorism and its appeal to the profession , see Sudgen (1991), Lewin (1996) and Hands (2001).

${ }^{10}$ For details of Samuelson's operationalism, see Hands (2001).

${ }^{11}$ Yet it is possible to argue that Samuelson's approach is compatible with a behavioristic perspective. See Lewin (1996).
} 
emphasis on choices in the explanation of economic behavior revealed strong positivist leanings. The debatable notion of hedonic utility gradually evolved to become an ordinal utility that refers to an index of a rational agent's preference ranking.

Samuelson's theory was a decisive move toward an explanation of behavior without reference to psychological items. Behavior is explained in terms of choice that is equivalent (by hypothesis) to the outcome of a utility maximization problem. With the revealed preference approach, the 'de-psychologizing' trend within economics was very close to its peak.

\section{THE CROWNING GLORY OF ECONOMIC ACCOUNTS FREE OF (EXPLICIT) PSYCHOLOGY}

The 'crowning glory' of economic explanations purged of any explicit psychology was reached when decision theorists succeeded in developing a utility framework applicable to the domain of uncertainty and risk. This section suggests that Savage's (1954) variant of expected utility theory yields an account that dispenses any psychology - the very explanation of behavior is centered on rational choice axioms and subjective probability rules.

\section{The origins of expected utility theory}

Risky choice is a phenomenon that has troubled social scientists. The origins of expected utility theory go back to the $18^{\text {th }}$ century, when Daniel Bernoulli (1738) developed a theory to explain the famous St. Petersburg paradox. Based on a gamble that yields an infinite monetary value, Bernoulli challenged the view that an individual was willing to pay to take part in a gamble in an amount up to its expected (monetary) payoff. He argued that the agent's willingness to pay to gamble revealed the expected value or utility she or he ascribed to it. On this basis, Bernoulli developed a theory of decision under uncertainty. He assumed that the value of a gamble corresponds to the weighted sum of expected utilities of its prospects (i.e., the sum of the multiplication of utilities of each outcome and the probabilities associated with them in every state of nature). From this perspective, individuals act in conformity with the expected utility maximization principle.

\section{Von Neumann and Morgenstern's axiomatization of expected utility analysis}

In the 1940s, economists became interested in advancing Bernoulli's treatment of expected utility so as to better explain risky choice. Yet, they were still troubled by the fact that the expected utility approach required a notion of numerical utility that seemed to conflict with their developed notion of ordinal utility (Starmer, 2000: 334).

John von Neumann and Oskar Morgenstern ([1944] 1947) found an inge- 
nious way of ensuring correspondence between the required cardinal scale and the ordinal utility function by formulating a set of axioms that allowed them to derive an expected utility theory. Like Bernoulli, they assumed that inferences about expected utilities were drawn from the objective probability and utility attached to the prospects. Unlike Bernoulli's approach, their expected utility theory was deduced from axioms and assumed that individuals extract different utility measures from gambles (Starmer, 2000). In vNM utility theory, the derived expected utility function is unique to a positive linear transformation. Numerical utility values may be assigned to gamble payoffs that preserve the agent's preference ordering. Preferable alternatives yield high cardinal utilities vis-à-vis less favorable prospects. Put somewhat differently, vNM utility axioms give rise to a cardinal utility approach in which individual's preferences for risky prospects are ranked by their expected utility values.

This approach implies that a pattern of choice satisfying the axioms will correspond to the decision output that in turn maximizes an individual's expected utility function. Note that the account of behavior underlying vNM expected utility theory appeals to consistency constraints on choice ${ }^{12}$. The foregoing technical conditions facilitate the derivation of an explanation of choice that does not rest on any particular psychological presupposition - individuals are assumed to make choices as if they drew optimal inferences about objective probabilities and outcomes.

One source of objection to the vNM expected utility approach is the premise that individuals make judgments based on objective probabilities. This simplifying assumption that agents know the distribution probability function of all events given by nature seems to constrain the framework's predictive and explanatory powers. In response to that, Leonard Savage (1954) proposed a reformed theory based on the notion of subjective probability (deduced from agent's preferences for risky gambles). This tricky maneuver gave rise to "the most brilliant axiomatic theory of utility ever developed" (Fishburn, 1970: 191).

\section{Savage's subjective expected utility model}

Savage's Foundations of Statistics provided a variant of expected utility theory built on a theory of subjective probability. In his perspective, probabilities are described as 'subjective' in the sense that they are derived from the agent's preferences over certain gambles. They reveal individual expectations about the outcomes associated with the perceived risky prospects ${ }^{13}$.

Savage's expected utility theory is deduced from a small set of axioms. His axiomatic constructs are compared with rules of logic that allow for a practical

\footnotetext{
${ }^{12}$ Sugden (1991).

${ }^{13}$ Subjective probabilities seem to be embedded in a 'belief-driven approach'. See Sugden (1991) and Starmer (2000).
} 
guide to rational choice. The subjective expected utility theory is presented as a normative (rather than a descriptive) theory. Its role is to inform agents about what choice behaviors meet the axioms of rationality and as such maximize individuals' expected utility functions. This version of expected utility theory became very popular among behavioral and social scientists and was applied to explain a wide range of phenomenon. It provides an explanation of behavior purged of any psychological content. In light of subjective expected utility framework, choice behavior is explained in terms of consistency (rationality) restrictions on individual preferences.

So Savage's approach seems to be the culmination of theoretical efforts seeking to make economics free from psychology. In the wake of this approach, economists explain any instance of behavior by only referring to a compact set of choice and probability axioms. Despite the popularity of Savage's theory it is worth considering two methodological issues that can be viewed as reasons for incorporating 'psychology' into economic analysis.

\section{THE RESURRECTION OF PSYCHOLOGICAL ECONOMIC MODELS AND ACCOUNTS}

Expected utility theory already met with some criticism in the 1950s as empirical evidence weighed against the hypothesis of expected utility maximization (Vickrey, 1945; Baumol, 1950; Edwards, 1954).

Herbert Simon $(1955,1997)$ and George Katona (1951) contributed significantly to reunification of economics and psychology. They made harsh criticisms of the unrealistic psychological assumptions underlying (expected) utility theory. Simon claimed that the neoclassical theory of choice yielded a distorted representation of actual behavior because it failed to recognize that individuals are equipped with bounded rationality (i.e., individuals have constrained computational capabilities for drawing optimal inferences and making choices). He argued that a psychologically realistic account of behavior would uncover heuristics (i.e. mental processes or routines) by which individuals make judgments and decisions. George Katona's main objection to 'economics without psychology' was that it offered an explanation silent about processes or mechanisms that give rise to behavior in the real economic world ${ }^{14}$.

This kind of criticism was not taken very seriously at the time. Most economists shared Friedman's methodological views that the strength of expected utility theory depended solely on its 'predictive power' rather than 'descriptive accuracy'.

\footnotetext{
${ }^{14}$ Quite similarly, Simon raised doubts about the notion of rationality on which neoclassical models were grounded. To him, rationality as maximizing behavior required agents to have a degree of knowledge that they could not occur in the real world. Harvey Leibenstein (1976) doubted that agents in the real world may feel the pressure required to the occurrence of maximization. For further details, see Frantz (2007).
} 
Since the general expected utility approach was thought to predict well many phenomena, many economists did not fret over responding to the early criticisms of expected utility framework on empirical grounds (Friedman and Savage, 1952).

However, the growing evidence that the utility framework failed to predict economically relevant phenomena led some economists to acknowledge two methodological problems. One concerns prediction of anomalies, i.e., empirical regularities that cannot be easily accommodated by mainstream choice theory. Another refers to advantages of building models of choice that uncover processes or mechanisms for behavior.

\section{Early evidence against the predictive power of expected utility theory}

In the 1950s, Maurice Allais challenged the empirical validity of expected utility theory. He argued that the standard approach to risky choice provided a wrong representation of individual risky preferences. His main objection related to the independence axiom, which states that if two lotteries have an identical branch of probability and payoff, their levels of payoff or probability will not affect agent's choice. Allais (1953) discusses two situations in which the above condition does not hold. He offers evidence that individuals often prefer a lottery that yields $\$ 5 \mathrm{~m}$ with a chance of $10 \%$ to another that gives $11 \%$ chance of winning $\$ 1 \mathrm{~m}$ and nothing with a chance of $89 \%$. He also shows that the same agents tend to prefer a sure gain of $\$ 1 \mathrm{~m}$ to a gamble that yields $\$ 5 \mathrm{~m}$ with $10 \%$ probability and $\$ 1 \mathrm{~m}$ with $89 \%$ chance.

On the basis of the independence axiom, the individual's preferences for winning $5 \mathrm{mi}$ would remain unaffected by changes in common consequence. Yet Allais showed that adding a chance of $89 \%$ chance at $\$ 1 \mathrm{~m}$ prompted a preference shift. This puzzle (or anomaly) within the mainstream body of analysis is called the 'common consequence effect'. Allais explains this empirical violation of independence axiom by suggesting that individuals are quite sensitive to changes in probability mass (for details, see Camerer, 1995) ${ }^{15}$.

In the late 1970s psychologists Daniel Kahneman, Amos Tversky, Paul Slovic among others designed experiments to further investigate the implications of expected utility theory for the purposes of prediction and explanation. For instance, Slovic and Tversky attempted to test empirically Savage's axioms of rational choice. In their experiments, subjects were told that their previous choices over

\footnotetext{
${ }^{15}$ Allais discovered yet another empirically grounded phenomenon that violated the independence axiom - the 'common-ratio effect'. Individuals often prefer a sure gain of $\$ 3000$ to a lottery that yields $\$ 4000$ with a chance of $80 \%$. Yet they tend to prefer a gamble that yields $\$ 4000$ with a probability of $20 \%$ to another that gives $\$ 3000$ with a chance of $25 \%$. Allais tried to explain this phenomenon by suggesting that, unlike expected utility theory predicts, individual preferences between pairs of prospects respond significantly to probability changes. When individuals face two pairs of gambles with a constant ratio of winning chances, they rely on the probabilities of the acts to make choices. For other empirical violations of the expected utility framework, see Camerer (1995).
} 
risky prospects revealed Allais and Ellsberg paradoxes. Individuals were then allowed to change their choices. Slovic and Tversky found that most participants did not shift their preferences even when they had the chance to do so.

This experimental literature identifying anomalies, paradoxes and effects highlight two important challenges for expected utility theory - one is prediction of economically significant behaviors regarded as anomalies, another is construction of an alternative model or theory that better explains how actual behavior happens and under what conditions the so-called choice anomalies may occur (and disappear). Nonetheless, most economists of that time were not really worried about dealing with these issues. Let me explain why that was so.

Thomas Kuhn's (1962) and Imre Lakatos' (1970) ideas might be useful to understand why economists hesitated to abandon expected utility theory in the face of anomalies. Both philosophers of science emphasize that it is always possible to disqualify a disconfirming piece of empirical evidence by suggesting that the problem does not lie with a model or theory under study but with poorly designed experiments ${ }^{16}$.

Furthermore, most economists were not concerned with the development of alternative models of choice that would describe processes or mechanisms underlying actual behavior. They left this cognitive task to psychology. This is because the standard expected utility framework was thought to make accurate predictions of a wide range of economic phenomena ${ }^{17}$.

Kahneman and Tversky's 1979 paper in Econometrica provided a tractable model of choice that better predicted and explained some expected utility anomalies. Their axiomatic model called 'prospect theory' accounted for risky decision in terms of a sequence of cognitive processes ${ }^{18}$. Unlike the expected utility framework, choices over a prospect are determined by a value S-shaped function that is defined in terms of gains and losses ${ }^{19,20}$. This accomplishment inspired many econ-

\footnotetext{
${ }^{16}$ Frey (1991) offers an overview of arguments against the significance and robustness of experiments detecting anomalies as puzzles within the body of economic theory.

${ }^{17}$ In their two famous papers on expected utility theory and its sources of criticism, Friedman and Savage argued that economic analysis would continue offering satisfactory predictions of empirical regularities within the economy, regardless of its silence about processes or mechanism for behavior.

${ }^{18}$ The framing stage consists of individuals' interpretations of the problem situation, in which they relied on certain mental shortcuts to draw inferences about contingencies, or alternative acts and their consequences. The evaluation stage is also dependent on how a situation is presented to the agent. Individual conceptual frameworks, norms, habits and values may shape this second stage. Finally, the editing stage refers to processes that enable individuals to further assess prospects and to select one with the highest value.

${ }^{19}$ Expected utility theory cannot predict important anomalies such as loss aversion and the endowment effect. The former (loss aversion) points to the fact that actual people care more about losing something rather than gaining something else of the same monetary value. The endowment effect refers to situations in which the amount individuals are willing to pay for something they do not have is less than the sum of money for which they would sell something they own.

${ }^{20}$ Prospect theory assumes that low probabilities are overestimated, whereas moderate and high pro-
} 
omists of the 1980s like Richard Thaler $(1981,1992)$ to investigate the positive implications of reunifying economics and psychology ${ }^{21}$.

\section{The revival of economic accounts with explicit psychological presuppositions}

By the late 1980s and early 1990s economists and psychologists had already collected various choice anomalies within the domains of intertemporal choice, decision under risk and social choice. It was only at that time that these pieces of evidence against the predictive and explanatory powers of choice theory motivated some economists to investigate whether their standard models of choice were built on strong idealizations and omissions that constrained their scientific purposes and therefore ought to be reformed. This issue begs the question of why this did not happen before. One possible explanation is that advances in game theory and experimental methods allowed economists to investigate the empirical validity of expected utility and to compare the predictive powers of standard theory with alternative analytical accounts offered by behavioral decision research like prospect theory (Starmer, 2000). As a result, economists could find that incorporating psychological variables into their models of choice would be worthwhile if this helped them to resolve economically relevant anomalies and eventually predict novel facts (Kahneman et al., 1986).

The early psychological economic models seem to be extensions of the (expected) utility framework. Practicing economists adopt an incremental strategy so as to come up with a model that yields improved predictions of actual choice behavior. Their accounts do not purport to challenge the core hypothesis of neoclassical choice theory; economists only add psychological assumptions that are thought to improve their predictions of actual behavior.

For instance, there are generalized expected utility models that relied on specific properties of expected utility functions and indifference curves to build a model to predict choice anomalies, such as the common ratio and the common consequence effects. These reformed models are extensions of the expected utility approach that provide an account of empirical deviations from expected utility theory by resorting to mathematical devices, such as indifference curves that fan out (Starmer, 2000). There are also expected utility models that take psychological variables rather explicitly. Two examples are the models of regret and disappointment developed by Robert Sugden, David Bell and Graham Loomes (Muramatsu, 2006).

Prediction of economically important choice anomalies seems to be the most important driving force behind the revival of the interdisciplinary field of psychological economics. One may wonder why behavioral economists opted for an incremental reformist strategy. This may be because the profession prefers progress

babilities are under weighted. The outcomes of a prospect are represented as positive and negative deviations from a baseline or reference point (a neutral outcome). See Muramatsu (2006).

${ }^{21}$ See Muramatsu (2006), especially chapters 2 and 3. 
in small steps and variants of the utility framework are not really perceived as a real threat.

There is another reason for putting psychology and economics back together. It has to do with the problem of identification of process or mechanism that offers genuine understanding of how decision-making happens in the world. Some behavioral economists and decision researchers have tried to address this complex issue. They do so by exploring Simon's influential models of bounded rationality that explain behavior in terms of search, stopping search and selection heuristics (Colinsk, 1996; Gigerenzer and Selten, 2001).

More recently, George Loewenstein and Colin Camerer develop models of choice that shift from an incremental strategy to a process-description approach. Driven by rather eclectic research methods, they explicitly suggest that theoretical (as well as empirical) progress of economic analysis depends on description of hidden processes or mechanisms significant for the occurrence of actual behavior. Some of their models draw on insights from neuroscience and (evolutionary) cognitive psychology so as to offer an improved understanding of how cognition and emotion might interact to bring phenomena of economic relevance, such as cooperation, intertemporal choice and risky decision (Camerer, Loewenstein and Slovic, 2005) ${ }^{22}$.

\section{CONCLUDING REMARKS}

This article is an attempt to offer an interpretation of the decline and subsequent revival of economic explanation based on explicit psychological assumptions and presuppositions. By reconstructing ideas posed by economists and decision theorists that have influenced our vision of the economic approach to behavior, I hypothesize that some methodological problems led followers of the Marginal Revolution to abandon the doctrine of psychological hedonism and to elaborate on accounts of behavior purged of psychological presuppositions. One refers to the issue of measurability of hedonic utility; another concerns the use of hedonism as a basis for positive and normative economic analysis with a level of objectivity and rigor similar to physics.

The first conclusion drawn from this paper was that Samuelson's theory of revealed preference circumvents the problem of grounding economic theory on a particular psychological doctrine. His approach offers an explanation of behavior in terms of observed choices that meet formal consistency requirements. Samuel-

\footnotetext{
${ }^{22}$ Nevertheless, there are important challenges posed to neuroeconomics. Our knowledge about how the information-processing architecture of the brain works to produce mental processes and behavior is still in its infancy, the usage of brain imagining techniques only shed light on correlations rather than robust causal processes, and there is no agreement among neuroscientists about the cerebral underpinnings of economic incentives and decision outcomes. Muramatsu (2006) addresses these issues in a thorough manner.
} 
son explicitly claims that observed choices suffice to explain economic behavior. In his perspective, observed choices reveal the rational agent's inner states. If this is so, Samuelson's analysis can fit to a behavioristic interpretation. In this case, it can be suggested that his revealed preference theory did not really remove all vestige of psychology from economic analysis.

The second conclusion is that Savage's subjective expected utility theory is regarded as the 'crowning glory of choice theory' due to its ability to account for phenomena without any explicit reference to psychological intuitions. Behavior is explained (predicted) by means of a compact set of rational utility and probability axioms.

SEU (Subjective Expected Utility) theory is the culmination of theoretical efforts to free economics from psychology. Nevertheless, some psychological presuppositions remain in Savage's utility framework. For instance, the independence axiom can be read as an implicit statement about the agent's ability to compare choice prospects.

My third conclusion is that decision researchers' willingness to resolve the problems of (i) prediction of anomalies and (ii) identification of significant processes and mechanisms for behavior explain (at least partly) the revival of psychological economic accounts. All this comes to challenge the widespread view that economic analysis does not need a behavioral foundation. Rather, such theoretical developments are in tune with the economic methodologist's vision that recurrent and robust anomalies serve as triggers of scientific innovations. Then, I end by paraphrasing the economist Paul Schoemaker - today's empirical puzzles to conventional wisdom offer the seeds for tomorrow's improved explanations of a complex phenomenon like decision-making behavior ${ }^{23}$.

\section{REFERENCES}

ALLAIS, M. ([1953] "The Foundations of a Positive Theory Involving Risk and Criticism of the Postulates and Axioms of the American School," In: Allais and Hagen, Expected Utility Hypothesis and the Allais Paradox. Dordrecht: D. Reidel

BAUMOL, W. (1951) “The Neuman-Morgenstern Utility Index: an ordinalist view,” Journal of Political Economy, vol. 59, 1, pp. 61-66

BENTHAM, J. (1781-1789) Na Introduction to the Principles of Morals and Legislation [Online] available from http://www.la.utexas.edu/research/poltheory/bentham/ipml/ipml.toc.html; accessed on March 25th 2007; Internet

BERNOULLI, D. ([1738] 1954) “Exposition of a New Theory of Measurement of Risk," Econometrica, vol. 22, no.1, Jan, pp. 23-36

BLACK, R.D.C., A.W. COATS and C.D.W. GOODWIN (1973) The Marginal Revolution in Economics. Durham: Duke University Press

BLAUG, M. (1997) Economic Theory in Retrospect, Cambridge: Cambridge University Press

${ }^{23}$ See Schoemaker (1982). 
BLAUG, M. (2001) “No History of Ideas, Please, We're Economists”. The Journal of Economic Perspectives, vol. $15, \mathrm{n}^{\circ} 1$, winter, pp. $145-164$

BRUNI, L. and R. SUGDEN (2007) "The Road Not Taken: how psychology was removed from economics, and how it might be brought back," The Economic Journal, 117, Jan., pp. 146-173

BOWLES, S. and H. GINTIS (2003) “The Origins of Human Cooperation,”In. P. Hammerstein (ed.) Genetic and Cultural Evolution of Cooperation, Cambridge: MIT Press

CAMERER, C. (1995) “Individual Decision-Making” In J. Kagel and A. Roth (eds.), The Handbook of Experimental Economics. Princeton: Princeton University Press

CAMERER, C. and G. LOEWENSTEIN (2004) "Behavioral Economics: past, present and future". In Advances of Behavioral Economics, C. Camerer, G. Loewenstein and M. Rabin (eds.), Princeton: Princeton University Press

CAMERER, C., G. LOEWENSTEIN and D. PRELEC (2005) "Neuroeconomics: how neuroscience can inform economics”, Journal of Economic Literature, vol. XLIII, March, pp. 9-64

CLARK, J. M. (1918) "Economics and Modern Psychology, I and II”, Journal of Political Economy 26, (Jan, Feb), pp. 1-30; 136-166

COATS, A. (1976) "Economics and Psychology: the death and resurrection of a research programme," In S. Latsis (ed.) Method and Appraisal in Economics, Cambridge: Cambridge University Press

COLINSK, J. (1996) “Why Bounded Rationality?” Journal of Economic Literature, 34, pp. 669-700

DOWNEY, H. (1910) “The Futility of Marginal Utility,” Journal of Political Economy, April, 18, 4, pp. 253 268

EDGEWORTH, F. (1879) “The Hedonical Calculus”, Mind, vol. 4, Issue 15, July, pp. 394-408

EDGEWORTH, F. (1881) Mathematical Psychics: an essay on the application of mathematics to moral sciences, London: Kegan Paul

EDWARDS, W. (1954) “The Theory of Decision-Making”, Psychological Bulletin, 41, pp. 380-417

GIGERENZER, G. and R. SELTEN (2001) Bounded Rationality: the adaptive toolbox, Cambridge: MIT Press

FISHBURN, P. (1970) Utility Theory for Decision-Making, New York: Wiley

FISHER, I. ([1892] 1965) Mathematical Investigations in the Theory of Value and Price, New York: A. M. Kelley

FREY. B. (1991) Economics as a science of human behavior: toward a new social science paradigm, Dordrecht: Kluwer Publishers

FRANTZ, R. (2007) "Leibenstein as a Behavioral Pioneer," In: Renaissance in Behavioral Economics. London: Routledge

FRIEDMAN, M. (1953) “The Methodology of Positive Economics," In: Essays of Positive Economics. Chicago: University of Chicago Press

FRIEDMAN, M. and L. SAVAGE (1948) “The Utility Analysis of Choice Involving Risk," Journal of POLITICAL Economy, vol. LVI, n ${ }^{\circ}$ 4, Aug, pp. 279-304

FRIEDMAN, M. and L. SAVAGE (1952) “The Expected Utility Hypothesis and the Measurability of Utility", Journal of Political Economy, 60, 6, pp. 463-474

HANDS, W. (2001) Reflection Without Rules: economic methodology and contemporary science theory. Cambridge: Cambridge University Press

HICKS, J. and R. ALLEN (1934) “A Reconsideration of Utility Theory”, Economica 1, 54, pp. 54-76 and 196-219

JAMES, W. (1890) Principles of Psychology, [Online] available from http://psychclassics.yorku.ca/James/ Principles.htm; accessed on March 23rd, 2007; Internet

JEVONS, S. ([1871] 1970) The Theory of Political Economy, edited by R. Collinson, Harmondsworth: Pelican

KAHNEMAN, D. and A. TVERSKY (1979) "Prospect Theory: an analysis of decision under risk," Econometrica, 47, pp. 263-291

KAHNEMAN, D., P. SLOVIC and A. TVERSKY (1982) Judgment under Uncertainty: heuristics and biases, New York: Cambridge UNIVERSITY Press 
KAHNEMAN, D., A. TVERSKY, J. KNETSCH and R. THALER (1986) "Fairness and the Assumptions of Economics," Journal of Business, vol. 59, $\mathrm{n}^{\circ}$ 4, part 2, pp. S285-S300

KATONA, G. (1951) Psychological Analysis of Economic Behavior, New York: McGraw Hill

KNIGHT, F. (1921) Risk, Uncertainty and Profit. Boston: Hart, Schaffner and Marx

KNIGHT, F. (1925) “Economic Psychology and the Value Problem”, Quartely Journal of Economics, vol. 39, $\mathrm{n}^{\circ}$ 3, May, pp. 372-409

KUHN. T. (1962) The Structure of Scientific Revolutions, Chicago: University of Chicago Press

LAKATOS, I. and A. MUSGRAVE (1970) Criticism and the Growth of Knowledge, Cambridge: Cambridge University Press

LEIBENSTEIN, H. (1950) "Bandwagon, Snob and Veblen effects in the Theory of Consumers'Demand," Quarterly Journal of Economics, vol. 54, pp. 183-207

LEIBENSTEIN, H. (1976) Beyond Economic Man, Cambridge: Harvard University Press

LEWIN, S. (1996) "Economics and Psychology: Lessons For Our Own Day, The Early Twentieth Century", Journal of Economic Literature, Sept., vol. 34, pp. 1293-1323

MARCHIONATTI, R. and E. GAMBINO (1997) "Pareto and Political Economy as a Science: methodological revolution and analytical advances in economic theory in the 1890s" The Journal of Political Economy, vol. 105, n 106 , pp. 322-1345

MCDOUGALL, W. (1910/1926) Introduction to Social Psychology, Boston: J. Luce and Co.

MILL, J. S. ([1843] 1967) A System of Logic, London: Longmans

MITCHELL, W. (1916) "Human Behavior and Economics: a survey of recent literature", Quarterly Journal of Economics, vol. 29, n 1 , Nov., pp. 1-47

MURAMATSU, R. and Y. HANOCH (2005) "Emotions as Mechanism for Boundedly Rational Agents: the fast and frugal way," Journal of Economic Psychology, 26, pp. 201-221

MURAMATSU, R. (2006) Emotions in Action: an inquiry into the explanation of decision-making in the real economic world. Erasmus University of Rotterdam, $\mathrm{PhD}$ dissertation

NEUMANN, J. von and O. MORGENSTERN ([1944]1947) Theory of Games and Economic Behavior, Princeton: Princeton University Press

PARETO, V. ([1900a] 1953) "On the economic phenomenon: a reply to Benedetto Croce". International Economic Association Papers, vol. 2, nº 3, pp. 180-196

PARETO, V. ([1900b]1964) "Sunto di alcuni capitoli di un nuovo trattato di economia pura del prof. Pareto" Giornale degli Economisti, March, pp.216-35 and June pp.511-545, reprinted in G. Busino, (ed.) Oeuvres Complètes, Geneva: Librairie Droz

PARETO, V. ([1901] 1953) “On the economic principle: a reply to Benedetto Croce”. International Economic Association Papers, vol. 2, n 3, pp. 203-207

PARETO, V. ([1906] 1971) Manual of Political Economy, New York: Augustus M. Kelley

RABIN, M. (1998) "Psychology and Economics," Journal of Economic Literature, XXXVI, pp. 11-46

RABIN, M. (2002) “A perspective on economics and psychology,” European Economic Review, vol. 46, iss.4, pp. 657-685

SAMUELSON, P. (1938). “A Note on the Pure Theory of Consumer's Behaviour,” Economica, 5, 17, Feb., pp. 61-71

SAVAGE, L. (1934) Foundations of Statistics, New York: Wiley

SCHILLER, R. (2001) Irrational Exuberance. New York: Broadway

SCHOEMAKER, P. (1982) “The Expected Utility Model: its variants, purposes, evidence and limitations" Journal of Economic Literature, vol. 20, $\mathrm{n}^{\circ}$ 2, June, pp. 529-563

SEN, A. (1977) "Rational Fools: a critique of the behavioral foundations of economic theory". Philosophy and Public Affairs, vol. 6, n ${ }^{\circ}$ 4, Summer, pp. 317-344

SIMON, H. (1955) "A behavioral model of rational choice," Quarterly Journal of Economics, 69, pp. 99118

SIMON, H. (1997) Models of Bounded Rationality: empirically grounded economic reason, vol. III. Cambridge: MIT Press

SLUTSKY, E. VON ([1915]1952) "On the theory of the budget of the consumer" In G. Stigler and K. Boulding (eds.) AEA Reading in Price Theory, Chicago: Richard Irwin Inc. 
SMITH, A. ([1759] 2002) The Theory of Moral Sentiments, Cambridge: Cambridge University Press

STARMER, C. (2000) "Developments in Non-Expected Utility Theory: the hunt for a descriptive theory of choice under risk", Journal of Economic Literature, 38, 2, June, pp. 332-382

STIGLER, G. (1950) “The Development of Utility Theory I," Journal of Political Economy, vol. 58, n 4, pp. 307-327

SUGDEN, R. (1991) "Rational Choice: a survey of the contribution from economics and philosophy". Economic Journal, vol. 101, n 407, Jul., pp. 751-785

THALER, R. (1981) “A Positive Theory of Consumer Choice," Journal of Economic Behavior and Organization, 1 , pp. 39-60

THALER, R. (1992) The Winner's Curse: anomalies and paradoxes of economic life. New York: Free Press

VEBLEN, T. (1909) “The Limitations of Marginal Utility" Journal of Political Economy, 17, 9, Nov., pp. 620-636

VICKREY, P. (1945) “Measuring Marginal Utility By Reactions to Risk,” Econometrica, 13, pp. 319-333 